\title{
What to do during inflight medical emergencies? Practice pointers from a medical ethicist and an aviation medicine specialist
}

Shu Fang $\underline{\mathrm{Ho}}^{1}$, BAcc(Hons), $T \underline{\text { Thirumoorthy }}{ }^{1,2}$, FRCP, FAMS, Benjamin Boon Lui $\underline{\mathrm{Ng}}^{3}$, MBBS, MSc

\section{INTRODUCTION}

During a recent overnight flight, the first author (a medical student) encountered a passenger requiring medical attention. The cabin crew immediately requested through the public announcement system that any 'medical personnel' present come forward to attend to the passenger. After several announcements, a passenger finally came forward and identified himself as a doctor. Fortunately, the passenger recovered and did not present as a medical emergency.

After the incident, the medical student questioned her inaction. As a medical student, should she have stepped forward to help if there was no medical doctor on board? What would her responsibilities and liabilities be if she did respond? And how would it be different if she were a medical doctor?

This article will first address the following: the duties and responsibilities of various parties in an inflight medical emergency; considerations before one responds to the inflight call for medical assistance; and what to do after identifying oneself as a medical doctor, based on practice pointers provided by an expert in medical ethics and professionalism. Next, it will discuss the aircraft inflight environment and the medical conditions that typically result from it, based on evidence in the literature. Finally, it will describe the factors that determine the need for flight diversion, based on practice pointers provided by an aviation medicine physician. The key messages from this article have been summarised in Box 1.

\section{Box 1. Key messages from the article:}

1. In an inflight medical emergency, a doctor is ethically obliged to step forward to help. Once the doctor steps forward, a duty of care is owed and a legal obligation is established.

2. The doctor should assess his own competence before stepping forward. He should openly communicate and collaborate with the pilot and crew, including the limits of what he can do, i.e. competency, specialty and level of training.

3. The role of the doctor is always to assist and support the pilot and crew. The pilot makes the ultimate decision for any plane diversion

4. Always get the patient's consent for any treatment and maintain written medical notes. It is important to know the key clinical information to communicate to the pilot and telemedicine ground crew.

\section{PART 1: DUTIES AND RESPONSIBILITIES OF VARIOUS PARTIES ON BOARD}

In an aircraft setting, the pilot, assisted by the co-pilot, has overall responsibility for the passengers, crew, flight and aircraft. The cabin crew manages inflight passenger services and communicates with the flight crew regarding situations occurring in the cabin that require the pilot's attention. The cabin crew is responsible for managing inflight medical emergencies. They are trained to recognise the symptoms of common medical problems and signs of medical emergencies. They are also trained to perform first aid and basic cardiopulmonary resuscitation and to administer medical oxygen using an oronasal mask. When required, they will request medical doctors among the passengers to come forward to assist in managing an ill passenger. ${ }^{(1)}$

There is no legal obligation for a medical doctor to step forward. However, doctors do have an ethical obligation to provide emergency care to patients on a humanitarian basis, unless "circumstances prevent him from doing $\mathrm{SO}^{\text {"(2) }}$ or "he is assured that others are willing and able to give such care." ${ }^{\prime(3)}$

The General Medical Council of the United Kingdom also states: "In an emergency, wherever it arises, you must offer assistance, taking account of your own safety, your competence, and the availability of other options for care." (4)

Once a doctor decides to respond to the inflight call for medical assistance, a duty of care is owed to the patient. ${ }^{(5)}$ The standard of medical care expected of a doctor on board an aircraft is no different from that expected of a doctor working in a wellequipped hospital environment. This means that the Bolam and Bolitho standards of reasonableness and responsibility (i.e. the skill reasonably expected of an ordinarily skilled doctor in a similar situation) will apply.

\section{The medical student}

A medical student should be aware of his own level of competency, act within his competency and not be overconfident in what he can do. When assessing his ability, he should ask: 'What is my physical and mental state? Am I sleepy, drowsy or fatigued? Have I recently consumed alcohol?' and 'What is the level of my medical training? Am I adequately trained to handle this emergency?'

The medical student passenger should inform the cabin crew that he is a student and, hence, would only be able to assist in the medical emergency in a limited capacity. He must remember

${ }^{1}$ Duke-NUS Medical School, ${ }^{2}$ Centre for Medical Ethics and Professionalism, Singapore Medical Association, ${ }^{3}$ College of Public Health and Occupational Physicians, Academy of Medicine, Singapore

Correspondence: Ms Ho Shu Fang, Medical Student, Duke-NUS Medical School, 8 College Road, Singapore 169857.shufang.dukenus@gmail.com 
that he is not qualified or licensed to administer prescription medications. His role is to assist the cabin crew and the doctor, if one has responded. He must not take over the primary management of the passenger who is ill. He should make use of the opportunity to watch and learn how the situation is being handled. The discussion that follows can help a medical student to be prepared for his next inflight medical emergency encounter.

\section{The medical doctor}

Likewise, a doctor should assess his own competency prior to offering assistance. This includes his physical and mental states, and level of training or familiarity in dealing with medical emergencies. Upon making a decision to step forward and help, a duty of care is owed to the patient.

These are the $5 \mathrm{Cs}$ that can be used to guide the Good Samaritan doctor when he is assisting in an inflight medical emergency:

- Competence: Always be mindful of the limits of one's competence and work within it. One's main job is to assess if the medical situation is an emergency or otherwise, and advise if the situation can wait until the arrival at the destination airport and what can be done during the duration of the flight.

- Communication: Communicate clearly with the passenger who is ill and the cabin crew. Disclose the limits of what one can do, i.e. competency, specialty and level of training. Communicate one's assessment of the situation to the passenger and cabin crew.

- Collaborate: Collaborate with the flight and cabin crew, the patient and the patient's family or accompanying persons. The airline crew is trained to manage inflight medical emergencies and basic resuscitation. Ask for available medical kits and direct the resuscitation if the situation requires one. Suggest options for managing the situation and balance the benefits and risks of treatment.

- Consent: Get consent from the passenger who is ill for any treatment or procedure, whenever possible. The consent process and documentation are no different from a consultation in a non-airline situation.

- Clinical records: Maintain medical notes and monitoring records after the incident. The doctor should keep the documentation for at least three years, as it is the limitation period in many (English law/Commonwealth) jurisdictions. Most airline staff will write their own reports.

\section{Professional liability: clinical negligence}

Good intention is not a protection against gross negligence or misconduct. It is wise to keep to the standard of care of an ordinarily skilled doctor. It is important to remember that not all airlines have insurance policies that indemnify the doctor.

The advice of the Medical Protection Society (MPS) is to do the best you can in the circumstances with the resources available, working within the limits of your competence. By responding to the inflight call for assistance in a medical emergency, the doctor has taken on the role of a Good Samaritan. MPS will assist the doctor with any problems arising from a Good Samaritan act anywhere in the world, whatever the jurisdiction of the aircraft the doctor is flying in. ${ }^{(6)}$

\section{PART 2: THE AIRCRAFT INFLIGHT ENVIRONMENT AND MEDICAL PROBLEMS}

Inflight environmental and physiological factors, which may be the cause of the medical emergency, can aggravate the medical condition or affect the treatment of the medical condition. These factors include: low cabin atmospheric pressure; low cabin partial pressure of gases, particularly oxygen; low cabin humidity, usually about $10 \%-20 \%$; and limitations on movement and space in the cabin.

The cabin altitude of commercial aircraft is usually between $5,000 \mathrm{ft}(1,500 \mathrm{~m})$ and $7,000 \mathrm{ft}(2,100 \mathrm{~m})$. At this altitude, atmospheric pressure decreases, causing gas within the body cavity to expand. The expansion of this 'trapped gas' can cause earache (air in the middle ear), facial pain (air in the paranasal sinuses), abdominal pain and distension (air in the intestinal lumen). If the passenger develops pneumothorax, the decreased atmospheric pressure in the cabin will result in the expansion of air in the pleural cavity and worsening of the pneumothorax. As a result of the lower cabin atmospheric pressure, based on Dalton's law of partial pressures, the partial pressure of oxygen in the cabin is lowered. Passengers with pre-existing hypoxia will be less tolerant of this environment.

Low cabin humidity causes mucosal dryness, exacerbating pre-existing conditions such as dry eyes. It may also exacerbate reactive airway diseases. ${ }^{(7)}$

\section{Common inflight medical problems}

Based on a review article ${ }^{(8)}$ that analysed inflight medical emergency calls from 1 January 2008 to 31 October 2010 $(n=11,920)$, the top six chief complaints of passengers are: syncope or pre-syncope (37.4\%, four deaths); respiratory symptoms $(12.1 \%$, one death); nausea or vomiting $(9.5 \%$, no death); cardiac symptoms $(7.7 \%$, no death); seizures $(5.8 \%$, no death); and abdominal pain ( $4.1 \%$, no death).

\section{Medical resources available inflight}

The Aerospace Medical Association, International Academy of Aviation and Space Medicine, and International Air Transport Association have made identical recommendations on first aid, emergency medical and universal precaution kits to be carried onboard commercial aircrafts. Many of the airlines also carry automated external defibrillators on board. The guidelines recommend that the medical kit is to be utilised only when a medically trained doctor is available to render help and treatment. The recommended content of the medical kit is listed in Table I.

When a doctor passenger responds to an inflight call for assistance with a medical emergency, he should ask for the aircraft medical kit to assess the available instruments and medications, and also conduct a proper physical examination on the passenger who is ill. The doctor will then be aware of what is available for use to treat the passenger's medical condition. The possible 
Table I. Recommended contents of an aircraft medical kit. ${ }^{(10)}$

\begin{tabular}{|c|c|}
\hline Medication & Medical equipment \\
\hline $\begin{array}{l}\text { - Epinephrine } 1: 1,000 \\
\text { - Antihistamine injectable } \\
\text { - Dextrose, } 50 \% \text { injectable, } 50 \mathrm{~mL} \\
\text { (single dose ampule or equivalent) } \\
\text { - Nitroglycerin tablets or spray } \\
\text { - Major analgesic injectable or oral } \\
\text { - Sedative anticonvulsant injectable } \\
\text { - Antiemetic injectable or Zofran (ondansetron) oral dissolvable } \\
\text { - Bronchial dilator inhaler with disposable collapsible spacer } \\
\text { - Atropine injectable } \\
\text { - Adrenocortical steroid injectable or similar oral absorption } \\
\text { equivalent } \\
\text { - Diuretic injectable } \\
\text { - Medication for postpartum bleeding (misoprostol, i.e. cytotec) } \\
\text { - Acetyl salicylic acid (aspirin) for oral use } \\
\text { - Oral beta blocker }\end{array}$ & $\begin{array}{l}\text { - Sphygmomanometer (electronic preferred) } \\
\text { - Stethoscope } \\
\text { - Oropharyngeal airways (appropriate range of sizes) } \\
\text { - Syringes (appropriate range of sizes) } \\
\text { - Needles (appropriate range of sizes) } \\
\text { - Intravenous catheters (appropriate range of sizes) } \\
\text { - System for delivering intravenous fluids } \\
\text { - Antiseptic wipes } \\
\text { - Venous tourniquet } \\
\text { - Sharp disposal box } \\
\text { - Gloves (disposable) } \\
\text { - Urinary catheter with sterile lubricating gel } \\
\text { - Sponge gauze } \\
\text { - Tape adhesive } \\
\text { - Surgical mask } \\
\text { - Emergency tracheal catheter (or large-gauge intravenous cannula) } \\
\text { - Umbilical cord clamp } \\
\text { - Thermometer (non-mercury) } \\
\text { - Torch (flashlight) and batteries (operator may choose to have one } \\
\text { per aircraft in an easily accessible location) } \\
\text { - Bag-valve mask } \\
\text { - Basic life support cards }\end{array}$ \\
\hline
\end{tabular}

approaches to medical conditions, such as cardiac arrest, acute coronary syndromes, stroke, altered mental status, syncope, trauma, dyspnoea, acute infections and psychiatric emergencies, in the setting of commercial flights with limited medical resources, were discussed in a recent review article. ${ }^{(9)}$

\section{PART 3: IN THE EVENT OF FLIGHT DIVERSION}

\section{Factors for flight diversion}

It is the pilot's decision whether to divert the plane or otherwise. The role of the doctor is to assist and advise the pilot. A review showed that $7.3 \%$ of inflight medical emergencies required flight diversion. ${ }^{(8)}$ The following situations would necessitate a recommendation for flight diversion: (a) one requiring immediate or urgent treatment, such as acute myocardial infarct, acute heart failure, acute respiratory failure or distress, and acute cardiovascular accident; (b) one requiring continuing cardiopulmonary resuscitation and support, especially in myocardial infarction, heart failure and respiratory failure/distress; (c) one requiring continuing treatment to maintain blood pressure (hypotension or severe hypertension), especially if it is difficult to manage or control blood volume depletion, causing moderate to severe hypotension; (d) unconsciousness; and (e) an obstetric emergency.

\section{Communication with telemedicine ground crew}

Unless the doctor knows how to communicate using the aircraft communication systems and the aircraft captain permits it, communication with the ground crew is usually done through the pilot or co-pilot. To facilitate ease of communication and avoid confusion in information transmission, it is advisable to write down the information that is to be transmitted to the ground crew and hand it to the pilot. It would be useful to convey the following information to the ground crew if a diversion is decided upon: (a) age and gender; (b) clinical impression and diagnosis; (c) types of emergency or urgent treatment needed; (d) consciousness level, heart rate, blood pressure, respiratory rate, body temperature (when appropriate), particularly the trends of these parameters; (e) description of injuries, if present; and (f) reason(s) for recommending a flight diversion, if required.

\section{CONCLUSION}

In summary, in an event of an inflight emergency, a doctor is ethically obliged to step forward to help. The doctor should assess his own competence before stepping forward. Once the doctor steps forward, a duty of care is owed. At all times, the doctor should openly communicate and collaborate with the pilot and crew, get the patient's consent for any treatment and maintain written medical notes. The role of the doctor is always to assist and support the pilot and crew. The ultimate decision for plane diversion is made by the pilot. It is important to know the key clinical information to communicate to the pilot and telemedicine ground crew.

\section{ACKNOWLEDGEMENTS}

Practice pointers on medical ethics discussed in this article were contributed by Dr Thirumoorthy Thamotharampillai and those on aviation medicine were contributed by Dr Benjamin Ng Boon Lui.

\section{REFERENCES}

1. Aerospace Medical Association. Medical Considerations for Airline Travel [online]. Available from: http://www.asma.org/publications/medicalpublications-for-airline-travel/medical-guidelines-for-airline-travel. Accessed June 8, 2015.

2. Singapore Medical Council. SMC Ethical Code and Ethical Guidelines (2002 and 2016 editions) and Handbook on Medical Ethics (2016 edition) 
[online]. Available from: http://www.healthprofessionals.gov.sg/content/ hprof/smc/en/topnav/guidelines/ethical_code_and_ethical_guidelines. html. Accessed June 8, 2015.

3. World Medical Association. WMA International Code of Medical Ethics [online]. Available from: http://www.wma.net/en/30publications/10policies/ c8/. Accessed June 8, 2015.

4. General Medical Council. Good medical practice [online]. Available from: http://www.gmc-uk.org/guidance/index.asp. Accessed June 8, 2015.

5. Shepherd B, Macpherson D, Edwards CM. In-flight emergencies: playing The Good Samaritan. J R Soc Med 2006; 99:628-31.

6. The Medical Protection Society Limited. Dilemma - dealing with an in-fligh emergency [online]. Available from: http://www.medicalprotection.org/uk/ casebook-and-resources/new-doctor/vol-5-no-2-2012/dilemma---dealing- with-an-in-flight-emergency. Accessed June 8, 2015

7. Lateef F, Tay C, Nimbkar N. Is there a doctor on-board?: medical liability during in-flight emergencies. Hong Kong J Emerg Med 2003; 10:191-6.

8. Peterson DC, Martin-Gill C, Guyette FX, et al. Outcomes of medical emergencies on commercial airline flights. N Engl J Med 2013; 368:2075-83

9. Nable JV, Tupe CL, Gehle BD, Brady WJ. In-flight medical emergencies during commercial travel. N Engl J Med 2015; 373:939-45.

10. Aerospace Medical Association. Medical Guidelines for Airline Travel: In-flight Medical Care [online]. Available from: https://www.asma.org/ asma/media/AsMA/Travel-Publications/Medical\%20Guidelines/In-FlightMedical-Care-July-2016.pdf. Accessed June 8, 2015 